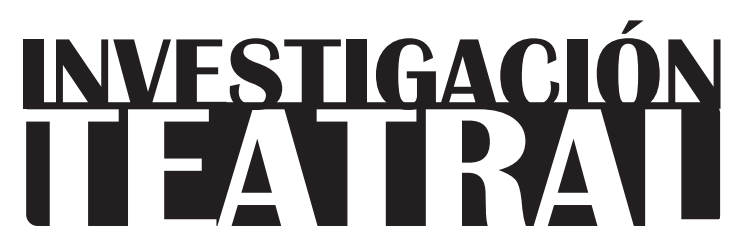

Revista de artes escénicas y performatividad

Vol. 12, Núm. 19

abril-septiembre 2021

Segunda época

ISSN impreso: 1665-8728

ISSN electrónico: 2594-0953

Universidad Veracruzana

Testimonio

\title{
El grupo teatral Tepito Arte Acá, proyectos de prevención de la violencia y el delito
}

Susana Meza Cosme*

* Tepito Arte Acá, México.
e-mail: susanameza@yahoo.com

Recibido: 30 de octubre de 2020

Aceptado: 08 de febrero de 2021

Doi: $10.25009 /$ it.v12i19.2671 


\title{
El grupo teatral Tepito Arte Acá, proyectos de prevención de la violencia y el delito
}

\section{Resumen}

Al grupo de teatro Tepito Arte Acá, fundado en 1980, se le confió la implementación de dos proyectos de artes escénicas en polígonos de altos índices de violencia en la alcaldía Gustavo A. Madero de la Ciudad de México, en 2013 y 2014. Posterior a ello, impulsamos talleres de verano de artes escénicas dirigidos a niñas y niños en el barrio de Tepito (2016, 2017, 2018, 2019). El presente testimonio aborda las fortalezas, experiencias y dificultades más significativas del grupo para enfrentar esta tarea.

Palabras clave: gestión teatral; pedagogía; talleres; jóvenes; niños; Ciudad de México.

\section{The theater group Tepito Arte Acá, projects to prevent violence and crime}

\begin{abstract}
The theater group Tepito Arte Acá, founded in 1980, was recently tasked with the implementation of two performing arts projects in Mexico City neighborhoods with high rates of violence. The group later promoted summer performing arts workshops aimed at children of the Tepito neighborhood. This article is a testimony of the group's most significant strengths, experiences, and difficulties in facing these tasks.
\end{abstract}

Keywords: theater management; pedagogy; workshops; youth and children; Mexico City. 


\section{El grupo teatral Tepito Arte Acá, proyectos de prevención de la violencia y el delito}

$\mathrm{E}$ l colectivo teatral Tepito Arte Acá fue fundado en 1980 por Virgilio Carrillo (México, 1957), tepiteño egresado de la Escuela Nacional de Arte Teatral. Toma su nombre del movimiento cultural que lo precede, forjado en los años setenta en el llamado "Barrio bravo" por artistas de diferentes disciplinas, como el muralista Daniel Manrique (México, 1939-2010), el escritor Armando Ramírez (México, 1952 -2019) y el restaurador de arte y pintor de caballete Julián Ceballos Casco (México, 1940- 2011), entre otros. En sus 40 años de trayectoria, el grupo se ha presentado en edificios teatrales institucionales y privados de la Ciudad de México, de varios estados de la República, así como de Los Ángeles, California, y de Bogotá, Colombia. Además se ha presentado en vecindades, bajo puentes vehiculares, patios de escuelas, canchas de basquetbol, atrios de iglesias de barrios y comunidades rurales e indígenas. Por mi parte, he participado en el grupo desde 1995. En un inicio, como asistente de dirección de Carrillo; más tarde, como codirectora y, finamente, como directora de mis propios montajes en los que Carrillo se desempeña como productor (Meza, La producción 12-60).

\section{Programas de prevención de la violencia y el delito}

Por su trayectoria y repertorio, el grupo fue invitado por la alcaldía Gustavo A. Madero (GAM), en la Ciudad de México, a participar en la realización del proyecto titulado Prevejoven en 2013, con apoyo federal del programa Subsidio para la Seguridad de los Municipios (subSemun) y Preveniños, en 2014, con apoyo federal del Programa Nacional para la 
Prevención Social de la Violencia y la Delincuencia (Pronapred) en los que participé como coordinadora y coautora de las obras teatrales presentadas.

Estos programas -Subsemun y, sobre todo, Pronapred-formaron parte de una tendencia latinoamericana en el ámbito de seguridad pública en la que se pasó de un enfoque punitivo a uno que intenta hacer énfasis en la prevención de la violencia y el delito (Chinchilla y Vorndran, Seguridad 7). Con ello se hizo eco a planteamientos de instituciones globales, como la Organización Mundial de la Salud (oms), ${ }^{1}$ el Programa de Naciones Unidas para los Asentamientos Humanos y la Oficina de las Naciones Unidas contra la Droga y el Delito, por mencionar algunos.

Una de las características de este tipo de estrategias es que se busca la cohesión interinstitucional y la multisectorialidad, esto es la participación de diferentes niveles de gobierno y de organismos de la sociedad civil. Cumpliendo con ello, a nivel federal en México se plantearon los lineamientos, estrategias y ejes rectores de los programas; se seleccionó a los municipios que recibirían esta subvención con base en una fórmula de elegibilidad y después se les ofreció un catálogo de acciones. A nivel municipal, se decidía tanto las acciones como el tipo de población a atender; por ejemplo, mujeres, juventudes, niñas y niños o personas en reclusión. Esto, sin dejar de invertir la mayor parte del presupuesto en la profesionalización y equipamiento de los cuerpos policíacos. Por último, quienes debían instrumentar las acciones de prevención de la violencia eran organizaciones de la sociedad civil (SEGOB, "Reglas para el otorgamiento” 4), como Tepito Arte Acá, constituido en asociación civil desde 2009.

Los proyectos en los que participamos -no fueron los únicos que implementó la GAMestaban constituidos por diferentes fases; en ellos, la principal herramienta eran las artes escénicas. Ya fuera que la compañía presentara su repertorio ante una nutrida asistencia de estudiantes de escuelas públicas de los polígonos (territorios estratégicos) asignados, o bien a través de talleres de artes escénicas dirigidas a jóvenes (2013) o a niñas y niños (2014), de los cuales, después de los procesos, presentamos sus trabajos teatrales ante la comunidad. En Prevejoven, además, se dio una tercera fase: la creación de una compañía juvenil de teatro.

\section{Prevejoven}

En la primera fase de Prevejoven se nos solicitaron 30 funciones de los espectáculos $\mathrm{Hi}$ dalgo: memoria y sangre y El país de Tanpendécuaro, ambas con dramaturgia y dirección de Virgilio Carrillo y mía, que acompañamos con 30 conciertos de Tlazohtiani, cantante

1 Cfr. informes sobre la violencia global que emite esta institución. 
INVESTIGACIÓNTEATRAL

Revista de artes escénicas y performatividad

Vol. 12, Núm. 19

abril-septiembre 2021
El grupo teatral Tepito Arte Acá, proyectos

de prevención de la violencia y el delito

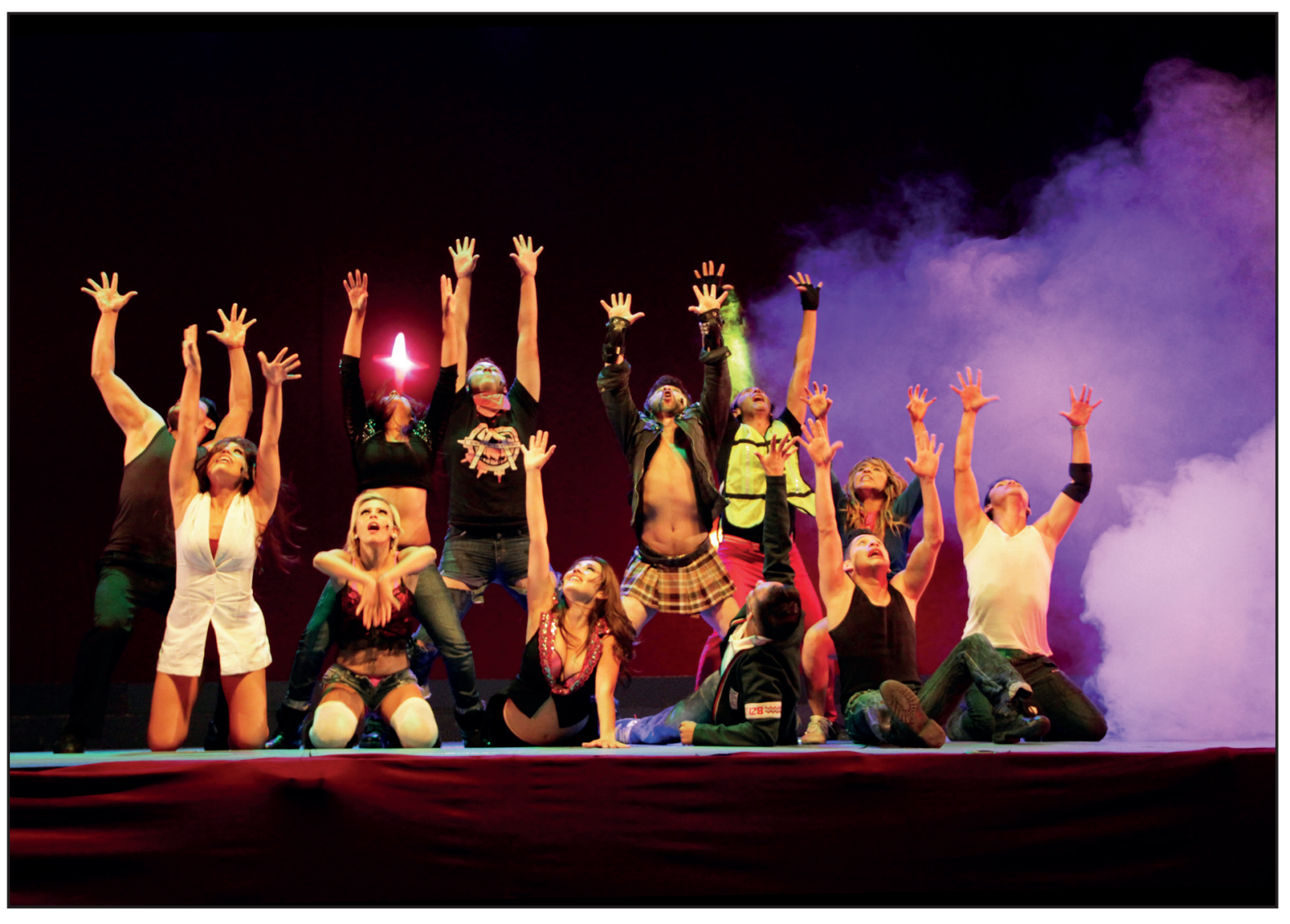

Imagen 1. Aspecto de la puesta en escena El país de Tanpendécuaro con dramaturgia y dirección de Virgilio Carrillo y Susana Meza con el grupo Tepito Arte Acá. Centro de la Juventud, Arte y Cultura, 2013, Futurama, GAM, CDMx, México. Fotógrafía de Susana Meza.

en lenguas indígenas, y su grupo Ixachilanka, en el Centro de la Juventud Arte y Cultura Futurama en 2013. Recibimos a un público compuesto por aproximadamente 9,000 adolescentes de escuelas públicas del polígono a intervenir.

La primera tarea que asumimos fue adaptar el lugar para las presentaciones. Esto, ya que el Futurama no tenía escenario, ni equipo de iluminación teatral, ni camerinos cercanos al lugar de representación, ni suficiente equipo de sonido para nuestros montajes, que contaban con una media de 15 ejecutantes, entre actores, bailarines y músicos. Para ello, instalamos varas, telones, bambalinones, piernas, iluminación -convencional y robótica-, camerinos, bodega para vestuario y equipo de audio con microfonía, pues se esperaba una gran audiencia y la acústica del lugar no era buena. Los micrófonos fueron inalámbricos para permitir la movilidad de los actores, que bailaban, corrían y brincaban (ver Imagen 1). 
El acondicionamiento del lugar no habría sido posible si no hubiéramos contado con parte de ese equipo, así como una buena relación con el proveedor, quien nos alquiló la logística faltante, y sin conseguir créditos bancarios personales para financiar todo el proyecto, pues el pago de éste llegó - a pesar de las promesas de que sería mucho antes- unos nueve meses después. El largo lapso transcurrido en la espera del pago no fue, en la trayectoria del grupo, un acto sorprendente; en vez de ello, constituye la difícil constante en nuestras relaciones con las instituciones. La falta de fluidez en el recurso tampoco fue una experiencia exclusivamente nuestra, como lo nota la organización México Evalúa en las aplicaciones de este programa en otros lugares (Suárez de Garay, Prevención 6).

También nos hicimos cargo de la difusión de las actividades. Por cierto, en vista de que para esta intervención y en posteriores de esta naturaleza logramos notas en periódicos y, alguna vez, en televisión, se puede afirmar que estas acciones tienen buena acogida en los medios de comunicación.

Comenzamos todo esto sin contrato de por medio. Pese a que parezca una sorprendente mala práctica, también es una constante en nuestra relación con las instituciones, pues esta formalidad legal suele aparecer, incluso, después de pagado el servicio. Además, supimos que hubo proyectos que iniciaron las acciones hasta que contaron con el contrato, ya sin tiempo de ejecutarlos, lo cual abría la puerta a la simulación.

Fuera de la incertidumbre legal y económica, el proceso de dar funciones fue gozoso. No sólo porque amamos hacer teatro ni porque era la primera vez, desde la década de los ochenta, que una institución nos pagaba tantas funciones, sino por tres razones más: la primera, la numerosa asistencia lograda por la Dirección Ejecutiva de Protección Civil y Seguridad Pública de la alcaldía, que coincidió con la misión que el grupo tiene: llevar sus espectáculos teatrales al mayor público posible; la segunda, que se trataba de una audiencia a la que dirigimos la mayor parte de nuestras obras: los estudiantes de educación media; la tercera razón es que nos permitieron mantener nuestro repertorio antisolemne y lúdico, que usa el humor, el lenguaje popular y el baile.

Nuestro trabajo teatral tuvo buena aceptación de los jóvenes, pero no necesariamente de las autoridades educativas. Por ejemplo, la directora de una escuela se molestó y canceló una nueva visita al Futurama porque dos estudiantes del sexo masculino se besaron luego de la representación del espectáculo El país de Tanpendécuaro, que incluye una escena titulada "Gayman al rescate". Es posible que la expectativa de algunas autoridades fuera que en las obras se les regañara a los jóvenes y se les conminara a "portarse bien". Si esta era la expectativa, les fallamos. Para nosotros fue una oportunidad de comunicar que el teatro es un lugar deleitoso, de libertad de expresión, y, por otro lado, nos sirvió para alentar la participación de los jóvenes en los talleres de artes escénicas (ver Imagen 2). 
INVESTIGACIÓNTEATRAL

Revista de artes escénicas y performatividad

Vol. 12, Núm. 19

abril-septiembre 2021
El grupo teatral Tepito Arte Acá, proyectos de prevención de la violencia y el delito

Susana Meza Cosme

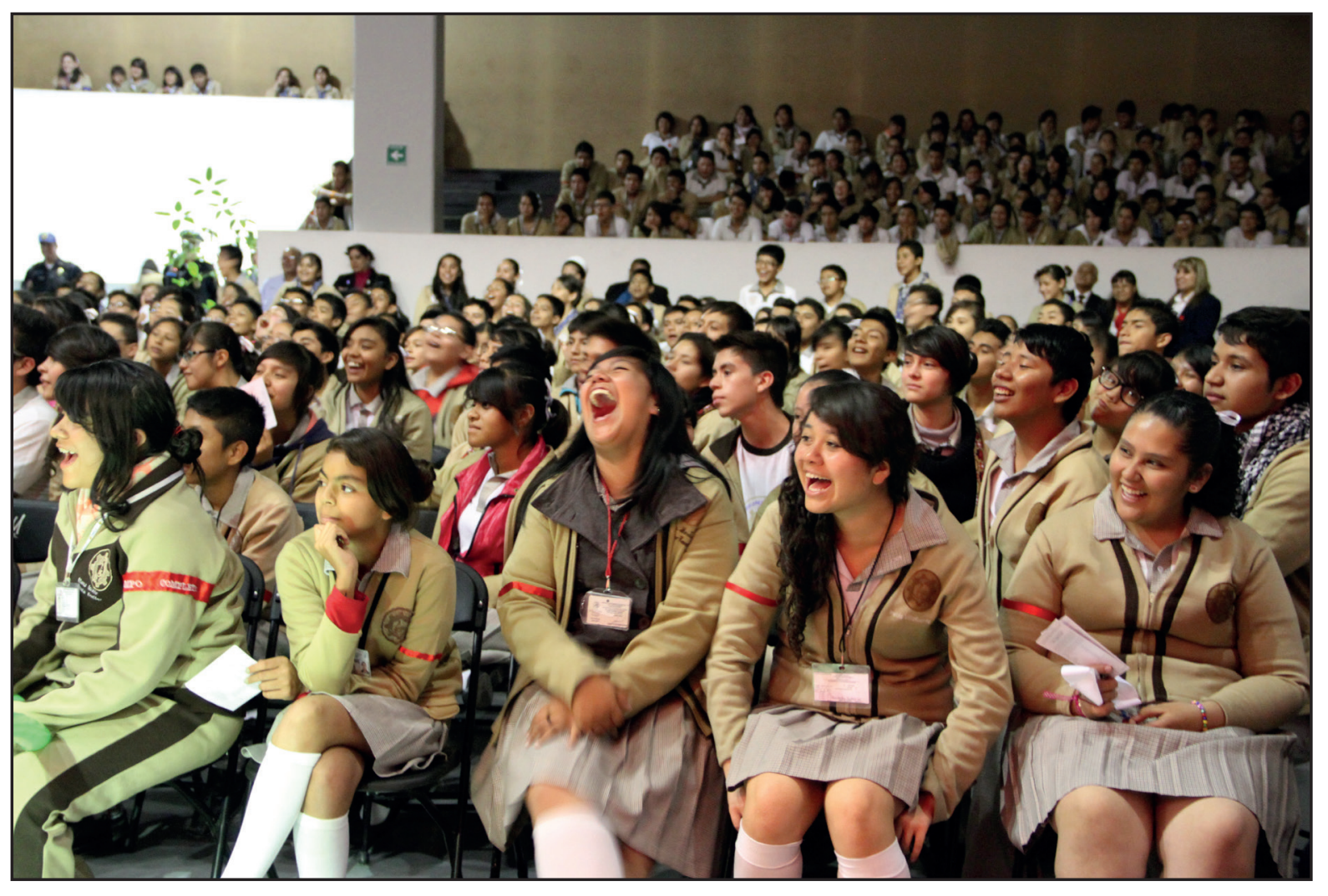

Imagen 2. Aspecto del público que asistió a las funciones del grupo Tepito Arte Acá dentro de la primera fase de Prevejoven. Centro de la Juventud, Arte y Cultura Futurama, GAM, CDMx, México, 2013. Fotografía de Susana Meza.

También se nos solicitó la creación de un montaje dirigido a jóvenes que se abocara a la prevención del abuso del alcohol, en el entendido de que el uso de sustancias es considerado uno de los factores de riesgo para la violencia. Así, escribí y dirigí Sé muy hombre, espectáculo en el que se explora cómo se une la narrativa machista de lo que un hombre debe ser con el abuso del alcohol en el ámbito familiar y en los medios de comunicación. Primero, la monté con los actores profesionales de Tepito Arte Acá y, después, se trabajó en uno de los talleres de artes escénicas para jóvenes que constituyeron la siguiente fase de Prevejoven.

En la segunda fase del proceso se atendieron 242 adolescentes en siete talleres ubicados en cinco espacios públicos de la alcaldía. Cada grupo tenía un maestro responsable del montaje escénico, un monitor y un maestro de danza, música y/o creación literaria. Aunado a estos especialistas en artes escénicas, la alcaldía mandó un equipo de psicólogas que trabajaban aptitudes para la vida con los jóvenes, aptitudes consideradas un factor de protección ante la vulnerabilidad frente a la violencia (OMS 7). 
INVESTIGACIÓNTEATRAL

Revista de artes escénicas y performatividad

Vol. 12, Núm. 19

abril-septiembre 2021
El grupo teatral Tepito Arte Acá, proyectos

de prevención de la violencia y el delito

Susana Meza Cosme

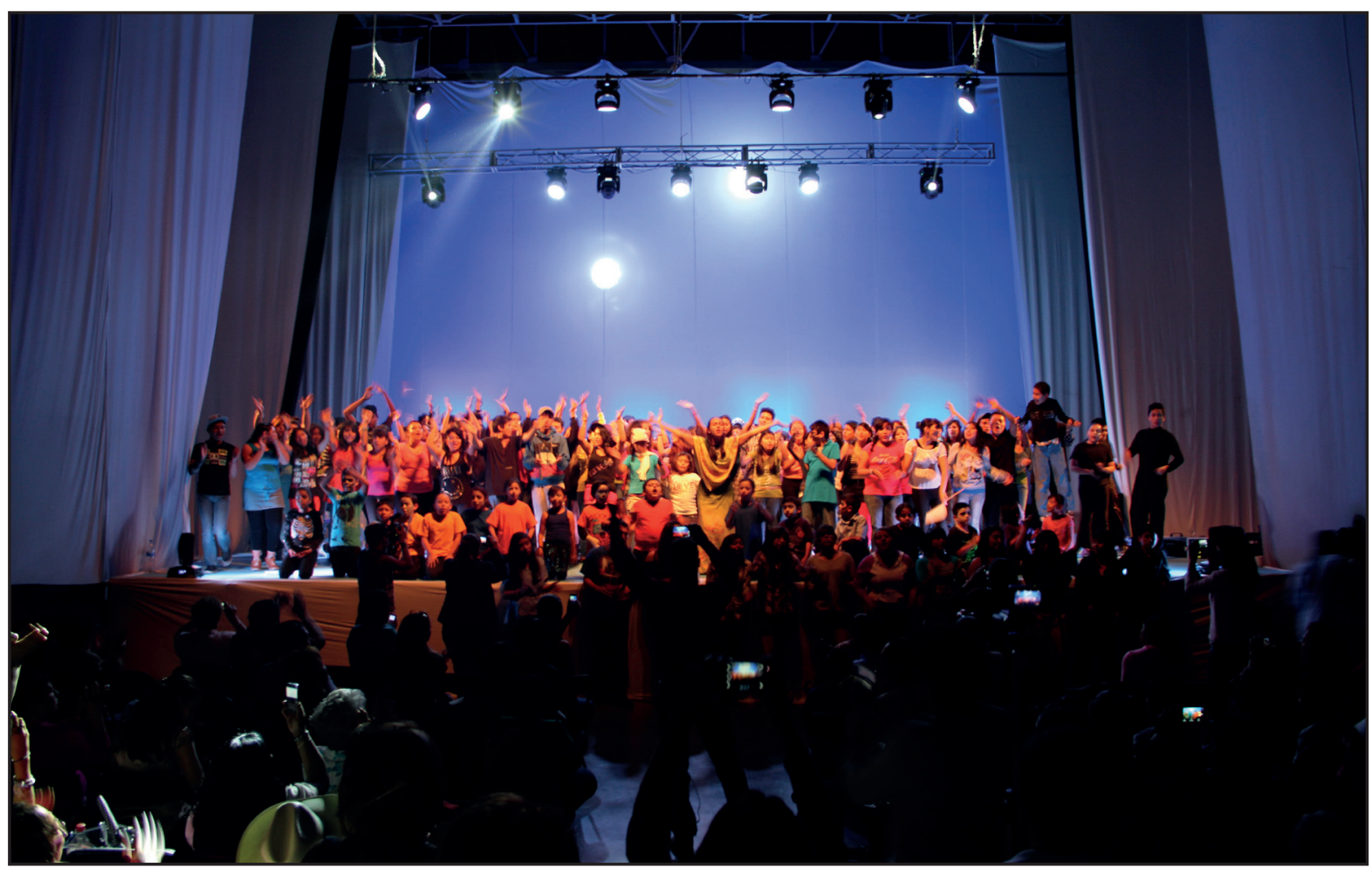

Imagen 3. Aspecto de la gala teatral de los talleres de artes escénicas en Prevejoven. Centro de la Juventud, Arte y Cultura Futurama, GAM, CDMx, México, 2013. Fotografía de Susana Meza.

Como coincidieron con las vacaciones de verano, la demanda de los talleres fue mayor a la esperada, así que abrimos dos grupos más e incorporamos a más maestros. Una parte importante de los estudiantes no esperados era de una edad menor a la que estipulaba la convocatoria. A estos niños y niñas no se les negó el acceso, considerando que era un proyecto con financiamiento público y como respuesta a cierta desesperación mostrada por las madres y abuelas de los infantes (en esta, y en posteriores emisiones de los talleres, no importaba cuánto bajáramos la edad permitida en la convocatoria, siempre llegaban madres o abuelas con niñas y niños menores a esa edad). Tampoco importaba cuánto más temprano se abriera el taller: antes de la hora de entrada ya había madres con sus hijos esperando y, en ese mismo sentido, no importaba cuánto se ampliara la hora de salida, siempre había niñas y niños por los que pasaban más tarde de la hora establecida. Entiendo esta alta demanda no por la popularidad de las artes escénicas entre la población, sino por la necesidad de apoyo en el cuidado de los más pequeños. Los talleres finalizaron con una gala en la que se mostraron pequeños montajes de todos los grupos ante familiares y amigos (ver Imagen 3). 
Conforme fuimos avanzando en las diferentes fases de Prevejoven se fue reduciendo la población atendida, pero se fue profundizando el trabajo escénico. En la tercera fase del proyecto se formó una compañía teatral juvenil con 15 integrantes que provenían de los procesos anteriores. Con ellos se realizaron tres montajes que se presentaron tanto en espacios públicos en la GAM, en la alcaldía Tlalpan de la Ciudad de México, y en Chimalhuacán, Estado de México.

\section{Preveniños}

$\mathrm{Al}$ año siguiente, en 2014, el orden de las fases en el proyecto de Preveniños se cambió sin mediar alguna razón, salvo una mayor incertidumbre de si lo habríamos de realizar o no. La primera fase fueron los talleres de artes escénicas, en los que se atendieron 185 niñas y niños, en cuatro espacios públicos de la alcaldía. No todos los maestros que participaron el año anterior con los jóvenes se sentían capacitados para dar clases a los infantes y entendían que era una mayor responsabilidad; por ello, tuvimos que invitar a otros artistas con experiencia en este ramo.

En los talleres de Preveniños aprecié que las zonas intervenidas contaban con infraestructura pública subutilizada. Muchas veces los vecinos ni siquiera se percataban de que existían estos espacios públicos. Esto podría tener las siguientes razones: porque la violencia provoca que la gente se recluya en su casa (Chioda, Fin a la violencia XII) o por una falta de programación y promoción pertinente de actividades en esos sitios. O la mezcla perniciosa de ambas. Cabe mencionar que la apropiación del espacio público para la convivencia comunitaria era una de las estrategias de Pronapred (sEGOB, "Acuerdo", 3), pues donde está ausente la comunidad se abre la oportunidad para la comisión de delitos.

En uno de los centros donde trabajamos, la directora me dijo que no me extrañara que nadie asistiera a los talleres de artes escénicas. Eso parecía muy probable, pues las instalaciones se encuentran en un camellón poco transitado. Incluso, a mí me resultaba un lugar desconocido, pese a la frecuencia con la que pasaba por allí. Por la incertidumbre de si participaríamos o no en Preveniños, se pasó el tiempo de hacer la promoción en las escuelas; lo que; a mi juicio, es lo más efectivo: con las personas encerradas en sus casas, la escuela se vuelve el lugar de encuentro por excelencia. Nos dimos entonces a la tarea de hacer la promoción en tianguis. Y pese a los malos augurios y lo precipitado de la convocatoria, la demanda-superó las expectativas nuevamente: en el centro donde "no iba a llegar nadie" tuvimos 60 niñas y niños divididos en dos turnos.

Un aspecto de tensión que surgía en los talleres era el "mal comportamiento" de los alumnos. Nos ayudó a enfrentarlo el hecho de que trabajamos en colectivo y nos apoyamos 
entre los diferentes maestros y monitores: a veces funcionaba un cambio de actividad, un cambio de grupo o dedicar un tiempo en exclusividad al niño o niña. Este tema lo toco porque me parece importante mencionar que, en los casos más difíciles, es tentador extenderles una invitación a que ya no asistan, pero cuando los escuchamos y testimoniamos los contextos tan retadores que enfrentan, pensamos que sumar más exclusión a su vida sería contrario al espíritu de estas iniciativas.

Otra de las dificultades que observé es que la dinámica de finalizar los talleres mostrando al público el trabajo de las niñas y los niños presiona a los maestros a buscar la excelencia en los espectáculos. Por esta razón, los profesores se sentían tentados a presionar, a su vez, a los estudiantes. Les recordamos que el objetivo de estos talleres es dotar de herramientas a los infantes para el desarrollo personal y para propiciar una convivencia gozosa. Aun más, limitamos el tiempo de duración de los montajes con el fin de reducir la presión sobre los maestros.

En la segunda fase de Preveniños ofrecimos, a cada una de las escuelas primarias públicas del polígono asignado, nuestra obra infantil Sucedió entre changos, acompañada del concierto de Tlazohtiani, para presentarla en sus patios en horario escolar. Esto lo hicimos pese a la sugerencia del área correspondiente de la alcaldía de realizar las funciones en la calle, a las puertas de la escuela, a la hora de la salida. Carrillo valoró que era un mal horario y las organizamos de otra manera. A la postre salió mejor realizarlas en los patios escolares, porque fue más fácil comprobar la implementación de la actividad. En ese momento no teníamos conocimiento de que, al momento de solicitar el cobro, debíamos presentar listas de asistencia. Por cierto, estas listas, como yo lo entiendo, habrían tomado mucho tiempo porque la meta de Preveniños era atender 4,000 infantes y, tal vez, las autoridades educativas no nos hubieran permitido realizarlas, pues imagino que para manejar datos privados de menores de edad se debe tener autorización de sus tutores. En cambio, solicitamos cartas firmadas por los directores de cada escuela en las que se especificaba la cantidad de niñas y de niños atendidos. Es mi especulación que, sin programar las funciones dentro de las escuelas y sin solicitar las cartas de sus directivos, tal vez no hubiéramos podido cobrar.

\section{Tepito Arte Acá después de Prevejoven y Preveniños}

Al final de Prevejoven, que oficialmente tenía una duración menor a un año, teníamos una compañía juvenil a la que le dimos continuidad en vista de la intensa participación e interés mostrada por los jóvenes. Más tarde, ellos continuaron con su formación profesional y hubo quien la siguió en el campo de las artes escénicas. Incorporamos a la compañía profesional de Tepito Arte Acá a quienes siguieron interesados en el teatro. Al principio 
INVESTIGACIÓNTEATRAL

Revista de artes escénicas y performatividad

Vol. 12, Núm. 19

abril-septiembre 2021
El grupo teatral Tepito Arte Acá, proyectos

de prevención de la violencia y el delito

Susana Meza Cosme

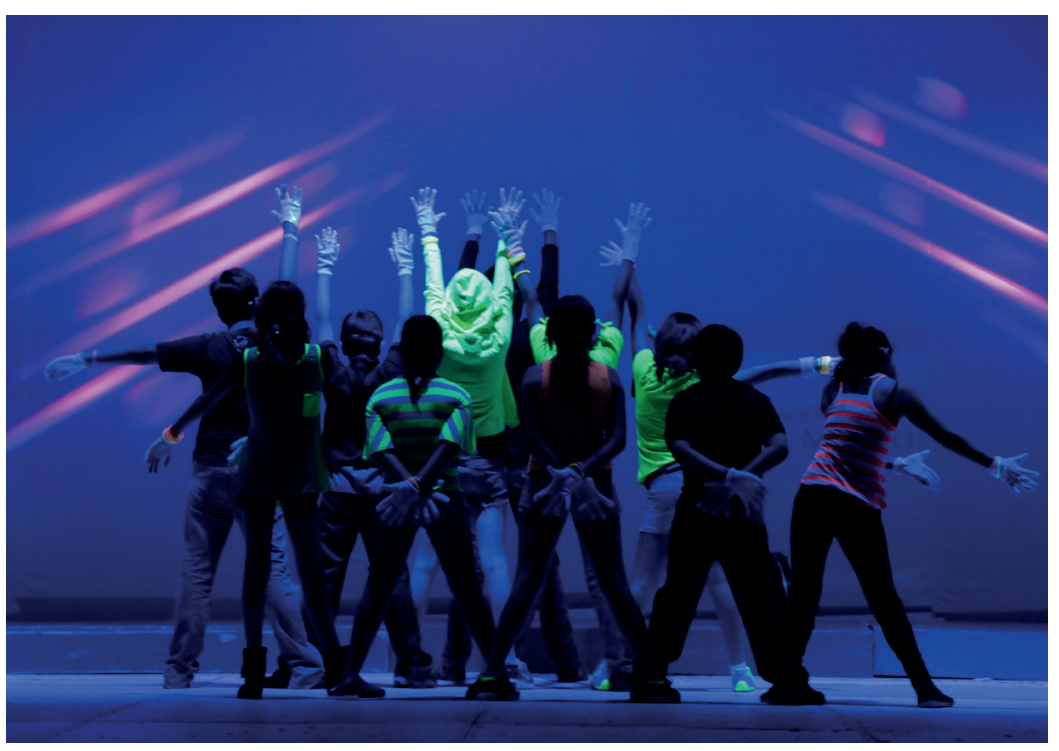

Imagen 4. Aspecto de uno de los montajes de los talleres de artes escénicas en Prevejoven. Centro de la Juventud, Arte y Cultura Futurama, GAM, CDMX, México, 2013. Fotografía de Susana Meza

participaron como comparsas. Con más tiempo y formación, algunos de ellos han realizado personajes protagónicos.

Por otra parte, debido a la buena recepción de los talleres de verano de artes escénicas para niñas y niños, decidimos implementarlos en el barrio de Tepito durante los veranos de 2016, 2017, 2018 y 2019. Los financiamos con el sacrificio personal, con la paciencia de nuestros colaboradores, con recursos que sacamos de otros proyectos y con el apoyo financiero de amigos generosos en vista de que, para sorpresa nuestra, no logramos conseguir apoyo institucional más que para el primero, aunque, en ese caso, al final tuvimos que coordinar talleres dirigidos a policías para poder recibir el apoyo económico.

Mantuvimos la dinámica de cerrar los talleres con la presentación de montajes con las niñas y los niños, pues la recepción de estos espectáculos siempre ha sido generosa y emotiva. Esta dinámica ha permitido la convivencia entre los alumnos de diferentes sedes, así como con las familias de los estudiantes. En emisiones más recientes de estas galas, para completar el convivio, organizamos la elaboración y consumo de alimentos. Los padres suelen mostrarse agradecidos y no escatiman su participación, los niños juegan después de las funciones y, generalmente, invitamos algún amigo músico que amenice el cierre de los talleres. De esta manera, se configura, por unas horas, una convivencia idílica en barrios marcados por la violencia (ver Imagen 4). Dice Itzel Cornejo, compañera de Tepito Arte Acá, entre broma y en serio, que estos talleres le dan la ganancia de caminar tranquila en las calles de Tepito, sabedora de que "el barrio nos respalda". 
Para finalizar este testimonio, mencionaré que tanto Subsemun como Pronapred se sometieron a diversas evaluaciones como las realizadas por la Auditoria Superior de la Federación o por la asociación civil México Evalúa, por mencionar algunas. En los primeros años de su implementación se lograron reducciones en los índices de comisión de delitos, pero se encontraron muchos aspectos susceptibles de mejora, referentes, la mayoría de ellos, a cómo evaluar el impacto de las intervenciones (Chapa, Prevención 6). En los proyectos en los que participé también noté debilidades vinculadas a la evaluación. Se requeriría un trabajo aún más profundo de transdisciplinariedad para mejorar el diseño de los proyectos. En cuanto a la implementación del proyecto, tal como se nos instruyó, considero que, pese a la incertidumbre y las numerosas dificultades, cumplimos con las metas propuestas e, incluso, fuimos más allá de ellas. Ello, gracias a nuestra experiencia, a nuestro trabajo colectivo y al amor que le tenemos a la escena, así como a nuestro público.

\section{Fuentes consultadas}

Chinchilla, Laura y Doreen Vorndran. Seguridad ciudadana en América Latina y el Caribe. Desafíos e innovación en gestióny políticas públicas en los últimos 10 años. Washington, DC: BID, 2018, http://www.thedialogue.org/wp-content/uploads/2018/11/LChinchilla_SegCiud_Nov2018_FINAL.pdf, consultado el 05 de noviembre de 2020.

Chapa, Lilian y Sandra Ley. Prevención del delito ¿Cuáles son las prioridades? Ciudad de México: México Evalúa / Centro de Análisis de Políticas Públicas, 2015.

Chioda, Laura. Fin a la violencia en América Latina. Una mirada a la prevención desde la infancia a la edad adulta. Sinopsis. Washington DC: Grupo Banco Mundial, 2016, https://openknowledge.worldbank.org/bitstream/handle/10986/25920/210664ov.pdf, consultado el 05 de noviembre de 2020.

Meza Cosme, Susana. La producción teatral del grupo Tepito Arte Acá de 1980 a 2015. Tesina de licenciatura, unAm, 2017, https://repositorio.unam.mx/contenidos?c=pQRg3x\&q=Tepito_.Arte\&t=search_0\&as $=1 \& \mathrm{~d}=$ false $\& \mathrm{a}=0 \& \mathrm{v}=1$, consultado el 30 de noviembre de 2020.

OMS. Informe sobre la situación mundial de la prevención de la violencia 2014. Resumen de orientación. Ginebra: oms, 2014. https://www.who.int/violence_injury_prevention/violence/status_report/2014/es/, consultado el 15 de noviembre de 2020.

SEGOB. "Acuerdo por el que se establecen los lineamientos para el otorgamiento de apoyos a las entidades federativas en el marco del Programa Nacional de prevención del Delito". Diario Oficial de la Federación, 26 de diciembre de 2014. 
INVESTIGACIÓNTEATRAL

Revista de artes escénicas y performatividad

Vol. 12, Núm. 19

abril-septiembre 2021
El grupo teatral Tepito Arte Acá, proyectos

de prevención de la violencia y el delito

SEGOB. "Reglas para el otorgamiento de subsidios a los municipios y, en su caso, a los estados cuando tengan a su cargo la función o la ejerzan coordinadamente con los municipios, así como al Gobierno del Distrito Federal para la seguridad pública en sus demarcaciones territoriales". Diario Oficial de la Federación. CDMx: 31 de enero de 2013, http://dof.gob.mx/nota_detalle.php?codigo=5286284\&fecha=31/01/2013, consultado el 30 de noviembre de 2020.

Suárez de Garay, María Eugenia et al. Prevención del delito en México: ¿Cómo se implementa? Una evaluación de acciones financiadas por el PRONAPRED en Nezahualcóyotl. CDMx: México Evalúa / Centro de Análisis de Políticas Públicas, 2017, https:// www.mexicoevalua.org/prevencion_neza/, consultado el 20 de noviembre de 2020. 